\title{
Professions as the conscience of society
}

\author{
Paul Sieghart Barrister, Gray's Inn, London
}

\section{Author's abstract}

Ethics is no less of a science than any other. It has its roots in conflicts of interest between human beings, and in their conflicting urges to behave either selfishly or altruistically. Resolving such conflicts leads to the specification of rules of conduct, often expressed in terms of rights and duties. In the special case of professsional ethics, the paramount rule of conduct is altruism in the service of a 'noble' cause, and this distinguishes true professions from other trades or occupations.

If professional ethics come into conflict with national laws, the professional today can test the legitimacy of such laws by reference to internationally agreed legal standards in the field of human rights, and so help to perform the role of 'professions as the conscience of society'.

\section{Acknowledgement}

This paper was first given as a guest address at plenary Session IV of the World Congress on Law and Medicine held in New Delhi in February this year.

One of the most striking phenomena of our time has been the increasing confrontation between science and ethics. Hiroshima is usually taken as the symbolic mark of the loss of our innocence in this field, when it began to dawn on our modern world that even the pursuit of pure knowledge was no more morally neutral than any other human endeavour. Since then, we have had to grapple with the problems of pollution, and more recently with those of information technology. Currently, it is the turn of medical science. A mere glance at the agenda of this Congress is enough to show how many of the recent advances in the healing arts are now seen as presenting not only benign promises, but also potentially malign threats.

Others are far better qualified than I to speak about these new developments, their likely consequences, and the particular problems which these will present. I would prefer instead to address myself to a single phrase on our agenda which caught my eye: 'professions as the conscience of society'. Those few

\section{Key words}

Professions; professional ethics; State medicine; confidentiality; law; international law; human rights; torture. words raise a host of important questions which must $\stackrel{\text { के }}{\vec{\omega}}$ underline all our discussions, and perhaps I may think aloud about some of these for a little while.

The field is wide, and in the time available I can only $\vec{\omega}$ sketch some outlines with a very broad brush. I shall $\rightarrow$ not be able to include much detail, or to review any of $\vec{v}$ the extensive literature which already exists. Instead, I음 shall try to concentrate on a general framework in which a professional conscience can find its place in $\mathcal{\Phi}$ society.

\section{The foundations of ethics}

First, let me say a word about ethics. Even today, tbe $\vec{\infty}$ impression has still not been entirely dispelled amo igg. scientists that morality and ethics are somehơv망 unscientific, even irrational; that they cannot be studieds by the rigorous application of a critical discipline; and that they are not susceptible to analysis by the rules: of logical inference. In fact, this is quite fallacious: $\frac{\mathbb{Q}}{\complement}$ morality and ethics can be studied just as rigorously as $\Rightarrow$ any other subject. But the fallacy is a stubborn one, and $\frac{3}{3}$ it is the principal cause of the continuing lack of any? formal education in this subject in many medicalo schools, and I fear in many law schools too - even today, when our students probably need it more than ever.

But I should be exceeding both my brief and my competence if I were now to launch into an essay on theos foundations of ethics. Let me instead hazard just a few? propositions from this field, in order to introduce theo framework which is my concern today.

My first proposition is so elementary that it is too often forgotten: questions of morality and ethics can only arise for a human individual in the context of $a^{\mathrm{N}}$ relationship with some other entity. Let us take Robinson Crusoe on his island as the paradigm of at solitary human being. If we could imagine him alone ino empty space without even the island or the other creatures on it, I think we should find that he existed inf a moral as well as a physical vacuum, without mora!? claims, rights, or duties - unless, that is, he believes into a god or gods whose commands require him to behave in one fashion rather than another even when he is orf his own, as for example to worship or to pray on som given occasions. But as soon as we restore the island and्f 
its creatures, it becomes possible to present him with some moral problems. If, for example, he is hungry, there is a goat, and he has a gun, is it morally right for him to take the goat's life in order to prolong his own? If there is a tree and he has an axe, is it right for him to destroy the tree in order to build a hut for himself, or a boat in which to seek escape from his enforced solitude? (Daniel Defoe, his creator, might not have regarded such questions as moral problems in his own time; but his Jain contemporaries and today's ecologists and animal rights campaigners certainly would.)

The case of Robinson Crusoe in a state of solitude may seem trivial and obvious, and I use it only to illustrate what I conceive to be the starting point of all morality - namely that it can only come into existence in the context of a relationship between a human being and some other entity. In fact, the aspects of morality with which we are most familiar in our everyday lives arise in the context of relationships with entities whom we recognise to be fundamentally like ourselves - that is, with other human beings. For practical purposes, almost all our moral problems pose themselves in the context of inter-personal relationships.

Let me therefore return to Robinson Crusoe, this time at the stage when Man Friday arrives on his island. Those who have read the book will remember the shattering effect this had on Defoe's hero. From being the master of all he surveyed, he suddenly found that he had to share his world with another creature of his own kind. As a typical European of his time, he regarded Man Friday as illiterate, uncivilised, savage, and therefore inferior to himself. Yet even by the ethos of that time this savage native was entitled in certain fundamental matters to the respect due to another human being. Crusoe might have had no qualms about exploiting his labour; but there could have been no question, for instance, of killing him for his own sustenance, as he was accustomed to do with goats.

That fleeting mention of cannibalism serves to introduce my next elementary proposition, which is that inter-personal moral problems only present themselves to an individual when his or her interests come into conflict with the interests of another. Moral problems do not arise in a paradise of abundance where all wishes can be instantly gratified without anyone having to make any effort, let alone inflicting any hurt or deprivation on another. They arise only in our finite world of shortage and suffering, in which the gratification of our desires necessarily entails competition with others, and in which the pleasure of some is achieved only too often at the cost of the pain of others.

In that situation, let me again start with the simplest case where the inter-personal relationship is confined to two individuals - say you and me. We are both hungry and there is only one portion of water, or we may both need shelter and there is only one hut, which cannot accommodate two at a time. Our interests conflict. How are they to be resolved? In essence, we have two options: to compete or to co-operate. If we compete, we shall fight for the booty, and whichever one of us proves to be the stronger will get all of it, and the other will get none. If we co-operate, we shall share it on some terms - half each, perhaps; or you today and me tomorrow.

Note here that each of these options can be expressed as a rule of conduct - in the one case 'let the stronger win'; in the other case 'let each have a share regardless of strength'. And since morality is essentially about rules of conduct, each of these statements constitutes a moral precept, and the choice of one of them in preference to the other constitutes a moral choice perhaps the most fundamental of all moral choices, namely whether in any given situation we should prefer selfishness or altruism.

Both of these are powerful human instincts. Their origins are obscure, and theories which have been devised to explain them range from titanic conflicts between gods and devils to the currently fashionable science of sociobiology. Tempting though it is, I shall resist the urge to discuss the merits of these theories, and confine myself to the observation that I have never yet met a single member of the species homo sapiens who does not exhibit at different times (and often at the same time) a powerful urge to behave selfishly, and an equally powerful urge to behave altruistically. Indeed, in one sense mankind's whole moral universe is created by the tension between these two urges and their associated modes of behaviour. It is no accident that our emotions come in symmetrical pairs: love and hate, creativity and destructiveness, greed and generosity, envy and gratitude. Each of these is an aspect of the fundamental distinction which we all perceive between good and evil, however much our individual perceptions of these things may differ in detail. And the specific organ in our psyche which makes these perceptions is what we call our 'conscience'.

One last thought at this elementary level: once we have chosen a particular moral rule of conduct, we often find it convenient to express it in terms of 'rights' and 'duties'. We might say, for instance, that in a free market everyone has the right to help himself to whatever he can, and owes no duties to others to protect their interests. Or we might say that, in times of shortage, everyone has a right to a fair share of the scarce commodity, and everyone else has a duty to help him to get that share.

\section{Professional ethics}

With that introduction, let me come to the subject of professional ethics. Like other moral questions, those of professionals can only arise in the context of a relationship of which the simplest is that between a professional and his patient or client. Whatever the profession - whether it is that of the physician, the lawyer, the priest, or any other - the principal feature of such a relationship is that of a gross inequality of power. Almost by definition, the patient or client is weak, vulnerable, and in need of help: the professional 
is strong, skilful, and specially qualified to give that help. Instantly, therefore, a moral choice arises for the stronger of the two: should he follow the rule of selfishness and help himself to what he can at the expense of the weaker, or should he behave altruistically and share with him what he has to give?

Now the outstanding characteristic of all professions is that their members are bound - without exception or qualification - to choose the second of these modes of conduct, and not the first. The cardinal sin of any professional, and the prime ground for his expulsion from the profession, is to prefer his own interest to that of his patient or client. In an emergency, the physician must turn out at all hours of the day or night in order to minister to his patient's needs. So must the lawyer, and so must the priest. It is a grievous wrong for the physician to prescribe or perform an unnecessary procedure, or for the lawyer to advise or conduct an unnecessary lawsuit. Within a professional relationship, altruism is paramount and self-interest has no place. The professional has a duty, regardless of his own interests, to put his skills at the service of those who need them.

It is striking how profoundly this ethos differs from the rule of conduct applicable to every other market in the supply of goods or services. No merchant or shopkeeper is under any comparable obligation; nor are the suppliers of other services, however skilled. In order to diagnose and repair the faults which may arise in modern machinery or electronic devices, you may need training and skills comparable to those of the ancient learned professions. For that reason, you may even call yourself a professional, as many today do. Yet no one will expect you to behave otherwise than as an ordinary supplier of scarce skills in an open market that is, to pursue your own self-interest, provided only that you practise no overt deception. This, as it seems to me, is what ultimately distinguishes a true profession from any other trade or occupation.

So far, our play has only included two characters, and we have seen how possible conflicts of interest between them can create moral problems to be resolved by rules of conduct, in their turn expressed in terms of rights and duties. Let us now expand the cast by introducing a third person. Beween these three individuals there may now be as many as three interpersonal relationships, each of which may entail rights and duties. If there are conflicts of interest between these individuals, applying rules of moral conduct in the different relationships may lead to inconsistent answers - for example if the rule in one relationship would require an individual to do one thing, whereas the rule in another relationship to which he is also a party would require him to do something different. If that happens, there is then what one may call a secondorder moral problem, requiring a second-order rule for its resolution - that is, a superior rule which decides which of two mutually inconsistent primary rules is to prevail.

Let me illustrate this by a simple example. Jones is
Dr Smith's patient. He has an enemy called Evans, who makes his life so uncomfortable that Jones's health is imperilled. Jones asks Dr Smith to supply him with something to put into Evans's drinking water, which? will make Evans feel so ill that he will stop troubling $\overrightarrow{\vec{c}_{\text {? }}}$ Jones.

If Evans is also Dr Smith's patient, the probleno resolves itself quite simply. Dr Smith has duties to eack of Jones and Evans to use his professional skills ing order to maintain their respective healths, and heo would be in grave breach of that duty if he used his professional skills in such a way as to imperil the healthP of Evans. But suppose that Evans is not Dr Smith's patient; indeed that Dr Smith does not even know him. or know anything about him, so that there is no direc $\bar{B}$ relationship at all between them. Clearly, we would still say that Dr Smith must not accede to Jones's reques:because he has a duty not to use his professional skill to ${ }^{\omega}$ undermine the health of any other human being, even if no professional or other relationship subsists between them.

Now this conclusion is not nearly as obvious as i $\vec{k} \rho$ looks at first sight. Take, for instance, a parallel case inf the business world, where no professional duties are্ involved. Suppose that Jones and Smith knew perfectly well that by engaging in a business transaction to their mutual profit they would ruino Evans. Most businessmen will tell you that in a socigiryo based on free markets they owe no moral duty to theic competitors to ensure that these remain in business휠 Evans goes bankrupt, that just means that he was not as competent and efficient as Smith and Jones, and since्e the market is designed to encourage competence anc efficiency and to discourage their opposites, the disappearance of Evans from the market is to be viewe $\vec{B}$ as a good thing for everyone else in it.

Where then does Dr Smith's duty not to harm Evans's health originate? To this question there are two possible answers. One is to say that all human beings, by virtue of their common membership of thesame species, have at least as much of a relationship. with each other as is needed to derive a duty not to dog each other foreseeable harm. This is an attractive proposition, and in an ideal world one would certainlyo like it to hold true. But in the real world it does not in fact hold true - as for example in the businesso community. Why then in such a situation should professional act differently from a businessman?

The answer, I think, lies in a second criterion which distinguishes a true profession from any other trade onn occupation - namely that the professional serves $\sigma$ another more general cause in addition, and in a case of conflict superior, to the cause of the well-being of hise individual patients or clients. That cause is sometimes? called a 'noble' cause; and though the notion of nobility is both imprecise and currently unfashionable the labeb is convenient and I shall therefore adopt it here.

So, a physician serves the noble cause of the्षे promotion of health and the alleviation of suffering 2 and nothing that he does in any individual case must 
ever damage that cause. Likewise, in the case of the lawyer with which I am perhaps more familiar, the noble cause is the cause of justice. It is a universal rule of conduct for all lawyers that they must never knowingly be parties to the deception of a court, however much good that might do for their clients. Even if a wilful deception of the court might save his client from the gallows, a lawyer must not practise it. (Whoever it was who once said that a doctor's mistakes are buried six feet below ground, while a lawyer's mistakes swing six feet above it, may not have got it quite right: perhaps just a few of those swinging corpses in the bad old days were not lawyers' mistakes, but the consequences of their giving priority to the service of the noble cause of justice, even over the individual interests of their clients.)

I think we have now proceeded far enough to see the outlines of a framework in which we can place the ethical problems which will arise in the course of professional practice, on those occasions when we are faced with conflicting moral claims to be resolved. The first rule for true professionals is that in a conflict between one's own interest and that of the patient or client, the patient's or client's interest must always prevail. The second rule is that the service to one's noble cause must always be paramount, and that even the interests of the patient or client cannot override what that service demands.

I am of course far from saying that these two simple rules will, between them, give instant answers to all the ethical problems with which a professional may find himself faced in the course of his practice. Ethics is not as simple as that: would that it were. But I can claim at least this: if a professional always applies both these rules in their proper measure, he will never be guilty of unprofessional conduct, and his professional conscience will remain clear.

\section{The law}

So far, I have dealt only with morals and ethics, and I have not yet once mentioned the law - even though this is a Congress on Law and Medicine. This delay has been quite deliberate, for I am one of those who believes that laws should not be made if they will not be largely observed: that people will not observe them if they believe them to be morally wrong; and that the law should therefore broadly reflect public perceptions of what is morally right - or, in a democracy, what those whom the public elect to represent them in the legislature believe to be both morally right and acceptable to their constituents.

Now in recent years, many nations have enacted laws which profoundly affect the area we are discussing. Some are obvious candidates for consideration among us, such as those relating to abortion, euthanasia, sterilisation, experimentation on human embryos and so on; these are being discussed by other speakers at this Congress who are far more competent than I to deal with their consequences in the field of professional ethics. But there are other laws too whose effects are not so obvious, though they may be even more pervasive.

Of these, perhaps the most intractable problems are created by legislation designed to make health care universally available to all members of a country's population whenever any of them needs it, without payment at the time of need. In the United Kingdom, this takes the form of a National Health Service (NHS) of which we are justly proud. (In the United States, this idea is called 'socialised medicine', and seems to be feared as a great evil.) But one of the consequences of such a scheme is undoubtedly the creation of a whole new crop of problems of professional ethics, as there is added to the primary relationship between the physician and his patient a second relationship between the physician and the State which employs him. (Some of the conflicts which can arise from such relationships are of course already familiar from the fields of insurance and occupational health, where physicians are employed by insurance companies to examine and report on applicants for insurance policies, and by employers to examine and report on employees.)

Perhaps I can best illustrate the kind of problem which such legislation can create by an example from the United Kingdom. Before and since the creation of our NHS, it has been a generally accepted rule of medical ethics - as indeed it has always been everywhere else in the world - that a physician must observe strict confidence about the secrets which his patient confides in him, and must not use or disclose that information for any purpose other than the clinical care of that patient. This rule of professional ethics was, and continues to be, reflected in the English law of breach of confidence. But it has also always been part of the Common Law of England that, where someone employs someone else to bring something new into existence, and the necessary work is done with the employer's materials and in the employer's paid time, the resulting object is the employer's property. This led to the curious result that, where a patient confided secrets to a physician in an NHS hospital, the physician was bound to observe strict confidence about those secrets - but the clinical notes which he was bound to make under his contract of employment, and which he made on the hospital's writing paper, then became the property of the Secretary of State for Health, and therefore open to be read not only by that Minister, but (at all events in theory) by every other civil servant whom the Minister authorised to read them.

For thirty-five years and more we dealt with this problem in a typically British fashion, by means of a self-denying ordinance on the part of the Minister whereby he reassured Parliament at regular intervals that he would never in practice exercise this legal power without the consent of the physicians concerned. In fact it was only last year that this question was brought to a head at the time of the passage of the UK Data Protection Act 1984, designed 
to avert the threats which are thought to arise from the processing of sensitive personal information in computers, especially those used by agencies of the State. As a result, there will now be legally binding rules which will ensure that physicians and other health professionals will retain personal control over the health information relating to their patients, even though the records containing that information are technically the property of the State and its agencies.

But it is not only in countries with a State health service that conflicts of interest can arise between the State and its agencies on the one hand, and the patients and clients of professionals on the other, and in which laws can be proposed and enacted which will seek to resolve these conflicts in favour of the State. One need not even look as far as the monstrous laws enacted by tyrannical regimes from Hitler's and Stalin's onwards: even in open democratic societies, the State and its agencies have perfectly legitimate interests to prevent and detect crime, to collect taxes lawfully due, to keep out illegal immigrants, and much else. In order to do these things efficiently, the State may well believe that it ought to have access to the secrets which patients have imparted to their physicians, or which clients have imparted to their lawyers, and may seek to persuade the legislature to enact such laws. On such occasions, the professions concerned may well have the opportunity - and the duty - to function as 'the conscience of society', and indeed they are often vigilant to protect the interests of those whom they serve, by ensuring that there is a thorough public debate before the details of such laws are decided upon. This is exactly what happened in the UK last year over the Data Protection Act, and also over certain powers of search proposed in an early version of our new Police and Criminal Evidence Act. And yet, on some occasions, the resulting laws may not reflect what the professionals concerned believe to be the right ethical rules. What are they then to do?

Here we come to one of the most difficult and intractable problems, which has occupied the minds of moral and political philosophers for centuries. What is it about the command of a law that requires others to obey it? After all, it is not self-evident that all laws must always be obeyed. Were it otherwise, we would have been bound to obey even Hitler's notorious Nuremberg laws which led ultimately to the massacre of millions of Jews, Gypsies, Balts and others. How then do we distinguish between legitimate laws that ought to be obeyed, and illegitimate ones that ought to be defied? The answer cannot simply be the procedural formalities of enactment, or even the constitutional legality of the legislatures that enact them, for the legislature of the Third German Reich was perfectly competent under that country's constitution to enact the Nuremberg laws, and there are tyrannical regimes all over the world today enacting scandalously bad laws - often under states of emergency quite legally proclaimed under their constitutions.

In earlier centuries, this question was generally resolved by reference to religious belief. In the@ Christian tradition of the mediaeval Latin church, form instance, there was the famous maxim lex injusta non es $\bar{r}$. lex - an unjust law is not a law - the test of the justice? of a law being its consonance with the law of God as itc was manifested by divine revelation. In some parts of the world today, as for instance in certain Islamico republics, that is still the test, at all events as applied bye. the regimes currently in power. But this leads to an obvious difficulty, since the content of divine revelation differs substantially between differents religions. Christians, for example, do not regard ase consonant with divine law the mutilation of the limbsof thieves, which some Muslims (though by no means all) derive from a strict application of Sharia law. How then should a Christian surgeon, currently employedọ in an Islamic republic, respond when he is invited to amputate the hand of a convicted thief, if he knows thativ if he declines the invitation, the operation will instead be carried out with a blunt and rusty axe by the loca $N$ executioner? What is needed for the resolution of such? problems is a universal standard of legitimacy against $c_{s}$ which all laws can be tested anywhere on our planet, regardless of the local constitution, religion or culture. $\frac{\mathbb{\mathbb { D }}}{\mathbb{\mathrm { D }}}$

\section{Universal standards}

Happily, such a universal set of standards has quite recently come into existence, by the consent of fige international community of nations as reflected by adoption of what is now a fully developed code international human rights law, to be found in sucth instruments as the Universal Declaration of Human Rights, the twin United Nations Covenants, anc regional treaties like the European and Americar? Conventions on Human Rights and the Africar $\overrightarrow{0}$ Charter on Human and Peoples' Rights, not to mention a mass of more detailed treaties in specifi areas of this field such as the Slavery Conventions, the. Convention against Torture adopted as recently as las December by the United Nations General Assembly and many others.

This universalisation of standards of legitimacy fot. laws is closely paralleled by a similar process which has been taking place at the level of professional ethics where I need only mention the International Code of Medical Ethics, the Declaration of Tokyo, and other similar sets of rules which have been adopted by the international community of physicians organised in it s various international bodies. Similar standards ari being developed in the field of law enforcement, as for example the UN Code of Conduct for Law Enforcement Officials, the UN Body of Principles for the Protection of All Persons under any Form of Detention or Imprisonment, the UN Standar\$ Minimum Rules for the Treatment of Prisoners, and the emerging standards designed to ensure the independence from State control of the judiciary an the legal profession.

Today, therefore, if any professional - physician of lawyer - feels uncomfortable with a national law? 
proposed or enacted, which appears to conflict with what he conceives to be the ethical duties imposed upon him by membership of his profession, there are at long last internationally accepted standards to which he can refer, and which he can apply in order to test the legitimacy of the law in question.

Let me illustrate this by one final example. Article 5 of the Universal Declaration of Human Rights says that 'no one shall be subjected to torture, or to cruel, inhuman or degrading treatment or punishment'. The identical provision will be found in the UN Covenant on Civil and Political Rights which now legally binds over eighty of the world's nations, as well as in the regional Conventions which bind others. These provisions are absolute: they admit of no exception or qualification in any circumstances - even in times of war or other public emergency. In short, it is now common ground among international lawyers that torture is wholly impermissible in any circumstances, and that the torturer has joined the pirate as hostis humani generis - the enemy of all mankind. Any physician or lawyer invited by his local military or police commander to take any part whatever before, during, or after an interrogation in which violence will be used in order to extract information from a suspect is therefore legally entitled - and some would argue morally bound - to refuse that invitation outright regardless of what the laws of his own country may say.

Whether he can afford to maintain such a principled stance in the interests of his own survival and that of his family is of course another question which only he can determine in the light of all the circumstances of the case, including the demands made upon him by his personal and professional conscience. But in that situation, one of the most important factors could be the extent to which he can expect support from his professional colleagues, both nationally and internationally.

If I may leave this subject with one last word, it would therefore be this. Now that we have internationally agreed standards by which we can test objectively - and independently of our personal cultures and religious beliefs, or those of our own nations - the legitimacy of the laws and other binding rules imposed upon us by our governments and legislatures, it is of supreme importance that we should familiarise ourselves with these standards, and develop procedures for applying them in specific cases. Like most other human endeavours, this can only be done effectively if we combine and co-operate for the achievement of that end.

As professionals, we enjoy many privileges and advantages. But our societies give us these not only because they need our special skills, but because they know that - uniquely among all other occupations our ethic is not that of self-interest, but of altruism and unswerving service to a noble cause. That is a sacred trust, and it is one we must never betray. I therefore see it as one of the paramount obligations of all professionals, in whatever field they operate, to support and play their full part in all the initiatives which are currently being undertaken to sustain the new international standards in these fields, and to give all the help they can to their colleagues everywhere in the world who are working towards those ends sometimes at great personal risk to themselves and their families. This is perhaps the supreme way in which professionals can ultimately perform the role which the agenda for this Congress quite rightly assigns to them: to be 'the conscience of society'.

Paul Sieghart, 6 Gray's Inn Square, London WC1R 5AZ. Paul Sieghart is Chairman of the Executive Committee of Fustice (the British section of the International Commission of Furists), a Governor of the British Institute of Human Rights, and a Trustee of the European Human Rights Foundation. $\mathrm{He}$ is the author of The International Law of Human Rights (Oxford, 1963) and The Lawful Rights of Mankind (Oxford, 1985). 